\title{
2 Cinema documentário e autobiografia: \\ a construção do depoimento pessoal a partir da memória social
}

Sara Martin Rodrigues*

*Graduada em Comunicação Social (Rádio e TV) pela Universidade Estadual de Santa Cruz (UESC) mestre em Memória: Linguagem e Sociedade pela Universidade Estadual do Sudoeste da Bahia (UESB). Integrou dois grupos de pesquisa: Cultura Memória e Desenvolvimento, Cuncula dò Universidade de Braślia (UnB) e à Universidade de Brasilia (UnB), e Análise do Discurso, vinculado à UESB. Trabalhou durante três anos e meio com Publicidade e Propaganda, exercendo função de diretora de criação. Atualmente, atua como assessora de Comunicação Integrada E-mail:

sarinha.martin@gmail.com.

\section{Resumo}

Neste texto, objetivamos discutir a relação entre memória social e autobiografia a partir do filme Jogo de Cena, documentário realizado pelo cineasta Eduardo Coutinho, que tem como fio condutor o diálogo entre realidade e ficção a partir de depoimentos pessoais (baseados em trajetórias de vida) contados espontaneamente por mulheres comuns e recontados pela encenação de atrizes. Jogo de Cena constrói uma narrativa intencionalmente ambígua ao despertar reflexões não apenas acerca da base questionável do cinema documental enquanto captura do real, mas da própria realidade enquanto detentora e criadora de verdades.

Palavras-chave: Documentário, Autobiografia, Memória, Realidade, Ficção.

\section{Abstract}

This text aim to discuss the relation between the social memory and the autobiography from the movie Jogo de Cena, documentary directed by the film-maker Eduardo Coutinho, that had as conducting wire the dialog between reality and fiction from people's personal testimony (based on life paths) narrate spontaneously by ordinary woman's and recounted by staging of the actresses. Jogo de Cena builds deliberately an ambiguous narrative by awake reflections not just about the questionable base of the documentary cinema as capture of the real, but from the reality itself as owner and creator of truths.

Keywords: Documentary, Autobiography, Memory, Reality, Fiction. 
Pierre Nora (1993) identifica como fator determinante no desejo de memória de nossa época a problemática fundamental da nossa época a problemática fundamental da
questão da mundialização, processo pelo questão da mundialização, processo pelo
qual o mundo se torna um só e no qual os meios de comunicação de massa exercem um papel primordial. Nesta análise, o autor sugere um movimento de alteração do tempo, ou seja, a história passa a ser mais dinâmica, rápida, a duração do fato é a duraça da notícia o novo é que dá a duraç̃o da notícia, o novo é que dá as cartas e conduz as vidas, forjando a sensação de hegemonia do efêmero. Nesse momento, segurar traços e vestígios é a maneira de se opor ao efeito devastador e desintegrador da rapidez contemporânea. Ele explica que, hoje, o que nós chamamos de memória é, de fato, a constituição aterial daquilo que nos é inpossivel lembrar. Por isso, a memória materializou-se, ganhando "lugares" onde ela possa se cristalizar e garantir sua preservação.

\section{Considerações iniciais}

Diferentemente do filme ficcional, no documental o personagem geralmente se constrói no ato da fala. Quando composto por depoimentos, contados como uma espécie de testemunho, esse discurso, mediado pela fala, adquire uma dimensão de veracidade por seu condicionamento à esfera do real. São personagens reais, relatando aspectos ou fatos que se relacionam ao que chamamos de realidade. Portadora de aspectos físicos e abstratos, na qual costumamos afixar o selo da verdade em oposição ao que acreditamos ser o mundo da imaginação, da fabulação, da mentira, da criação, da ficção, essa realidade tem sua vitalidade ancorada na complexidade do enlace entre as falas produzidas pelos homens.

Sendo assim, o cinema, enquanto forma narrativa, ocupa um lugar de destaque na circulação desses discursos. No caso do documentário, que se constitui principalmente como um arquivo ou como um lugar de memória, do qual nos falou Nora (1993) ${ }^{1}$, faz-se mister entender como esses discursos se constroem não só tencionados pelo ato de produção cinematográfica, mas também pelas estruturas de organização sociais e, consequentemente, pelas vontades de poder que atuam sobre eles.

Refletir acerca desses discursos é sinalizar para o que entendemos por realidade, logo, por verdade. A partir daí, entramos na temática central do filme Jogo de Cena, aqui proposto como objeto de análise. Questionando sobre a relação entre realidade e representação, o filme nos conduz ao problema da natureza do depoimento e parece apontar para a ilusão de verdade à qual vivemos socialmente submetidos.

\section{O jogo encenado}

Foi na década de 1950 que o chamado cinemaverdade francês criou as sequências de interação entre personagens e equipe dentro do filme. Já o improviso de muitas situações, a precariedade de algumas tomadas, as imagens em movimento nas chegadas aos locais são tributárias dos cinemas novos que surgiram 
nos anos 1960, das tecnologias mais leves e da experiência da televisão (LINS, 2004).

No cinema brasileiro, essa tendência autorreflexiva, que tenta provocar no espectador uma postura consciente frente aos mecanismos que agem sobre o filme, encontrou resistências. Só a partir dos anos 1980, a nova produção documental do Brasil assinalou, em alguns de seus filmes, a preocupação em reposicionar o estatuto do documentário, isto é, em abordar o objeto documentado de forma inovadora. Dessa vertente cinematográfica, comprometida com o anti-ilusionismo no campo audiovisual, nasce o documentário de Eduardo Coutinho. Ao longo de sua trajetória cinematográfica e através de seus filmes, é possível observar o questionamento do documentarista em relação à pretensa objetividade assumida pelo documentário.

Buscando evidenciar as marcas de produção do filme, ao invés de escondê-las para garantir sua isenção, Coutinho faz questão de desvelar seus filmes, apresentando-os como um ponto de vista, uma perspectiva, uma visão pessoal sobre dada questão. Em suas produções, esse objetivo é alcançado através da percepção do processo de construção dos filmes. Observamos que perguntas direcionadas aos personagens durante as entrevistas não são excluídos na montagem, há diálogo, há questionamento e há, sobretudo, a evidência de uma postura parcial. Vemos a figura do diretor, da equipe e dos mecanismos de produção. Assim, o uso da metalinguagem que se faz visível dentro da trama parece ter a intenção de conscientizar o espectador acerca da possibilidade de manipulação, do aspecto direcional da narrativa; é o cinema que fala sobre si, que se desnuda enquanto conta suas histórias.

Bernardet (1985) compreende que o cinema autorreflexivo não pretende dar a impressão de algo real, seu intuito é significar e assumir esta significação de mundo. Seguindo a proposta da visita ao mundo alheio, descobrindo crenças, alegrias, medos, fantasias e sonhos nas histórias e trajetórias de vida do "outro", o método coutiniano encontrou na biografia de 
anônimos, no dia a dia dos homens comuns, a beleza da alteridade. Com admirável maestria, o diretor consegue tornar interessante o banal, sem ter que apelar para os recursos ilusórios e alienantes, reiterando, através de seu reconhecimento por parte da crítica e do público, a ideia de que a magia do cinema não está restrita ao ilusionismo audiovisual (LINS, 2004).

Relacionando o cinema documental ao ficcional, a partir dos estudos de Nichols (2005), temos que ambos não são estruturas tão estanques como se costuma imaginar. Aliás, o cinema antiilusionista se utiliza dessa problemática como meio e fim, misturando documentário e ficção para elucidar aspectos importantes e vitais de cada um, além de revelar que o percurso entre um e outro não é assim tão distante como se convém pensar. Para Deleuze (2007), a partir do cinema moderno, na imagem denominada por ele de imagem-tempo, não se sabe mais o que é imaginário ou real, físico ou mental, não que sejam confundidos, mas porque não é preciso saber, e nem mesmo há lugar para a pergunta. "É como se o real e o imaginário corressem um atrás do outro, se refletissem um no outro, em torno de um ponto de indiscernibilidade" (DELEUZE, 2007, p. 16).

Apostando nessa ideia da verdade poder ser constituída independente de uma origem, modelo ou essência que se opõe ao que entendemos por mentira, enfim, acreditando que ela tem em si a "potência do falso" (não num sentido pejorativo, mas uma potência de caráter criativo), foi que Eduardo Coutinho criou Jogo de Cena (2007), seu décimo longa-metragem, o qual tomamos como objeto de análise deste texto.

Partimos de um estudo que pretende refletir acerca da relação travada entre o fenômeno da memória social e os discursos testemunhais que permeiam Jogo de Cena. Utilizamos, portanto, um embasamento teórico-metodológico multidisciplinar, devido ao assunto em pauta referir-se ao campo da memória, buscando como bases de pesquisa utilizar a sociologia de Halbwachs (2004), para tratar de memória social; e, no âmbito da teoria 
cinematográfica, procuramos nos apoiar nos estudos filosóficos de Deleuze (2007), no que diz respeito ao tempo e à duração aplicados ao cinema, Nichols (2005) e Ramos (2004) para pensar uma possível conceituação para o termo documentário, além de Lins (2004), a partir de sua obra dedicada à análise fílmica das obras de Eduardo Coutinho.

Jogo de Cena começa com a imagem de um anúncio no jornal com a seguinte mensagem: "CONVITE - Se você é mulher com mais de 18 anos, moradora do Rio de Janeiro, tem histórias pra contar e quer participar de um teste para um filme documentário, procure-nos. Ligue a partir de 17 de abril (10 às 18h) para 3094-0838 / 3094-0840”. O filme segue com o depoimento de uma atriz, conhecida pelo grande público, narrando trechos de sua suposta trajetória de vida. Os depoimentos se seguem, sendo intercaladas mulheres comuns e atrizes famosas. A mistura entre ficção e realidade parece extrapolar seus limites quando percebemos que os discursos das atrizes são, na verdade, encenações baseadas nos conteúdos das falas das personagens "reais". Por vezes fragmentados e com histórias que se repetem, esses discursos deixam a narrativa estonteante e a mente do espectador, possivelmente, bastante confusa quanto ao julgamento sobre verdade e mentira.

Para aproximar ainda mais as noções de realidade e ficção, assumindo também uma postura um tanto metafórica, do início ao fim o filme se passa dentro de um teatro, onde, a cada quadro, aparecem as personagens, uma de cada vez, sentadas numa mesma cadeira, de frente para Coutinho e de costas para o local destinado à plateia. Não há movimentos de câmera, nem muitas mudanças de enquadramento, a iluminação permanece a mesma para todas as personagens. É como se o cenário se anulasse, transformando-se no rosto, na fala, na voz, no sentimento à flor da pele, na verdade e na mentira. As cadeiras vazias em plano de fundo atuam na imagem, apontando-nos o nosso lugar de espectadores diante do “espetáculo". 
${ }^{2}$ A faixa comentada, em que Coutinho, o diretor João Salles e o crítico Carlos Alberto Matos conversam a respeito de Jogo de Cena, encontra-se na opção "Extras" do filme.
As atrizes convidadas por Coutinho para participar do filme encenando os discursos contados pelas não atrizes, repetindo, reiterando e até mesmo alterando esses discursos ditos "reais", também foram convidadas a incorporar partes de suas histórias de vida e pensamentos pessoais às histórias que interpretam, colocando-nos ainda mais em xeque quanto ao que decidiremos acreditar. Podemos notar também pequenas analogias, sinais que nos levam a pensar na questão central do filme. É o caso da personagem Maria de Fátima, designer de sobrancelha. Seu trabalho consiste em pintar sobrancelhas com uma tinta que fixa à pele, para dar a impressão de completude no desenho dos pelos, escondendo os locais onde existem falhas. Desse modo, a sobrancelha passa a ser parte "real", parte "ilusória", assim como os depoimentos que compõem toda a narrativa fílmica

Mesmo vendo e ouvindo, em alguns momentos, entre um discurso e outro, a conversa de Coutinho com as mulheres, sobre a sensação de estar contando sua trajetória de vida, no caso das não atrizes, e encenando a vida do outro, no caso das atrizes, esse fator não elimina o incômodo referente à impossibilidade de certeza acerca dos fatos que são contados pelos sujeitos. As próprias atrizes descrevem a dificuldade que sentiram para encenar não um personagem fictício, mas uma pessoa do mundo real, uma história que de fato ocorreu. Outras, por não serem conhecidas pelo grande público, passam despercebidas, pois o filme não revela onde estão todas as encenações, é preciso recorrer aos extras se quisermos descobrir quem, de fato, estava contando as suas histórias e quem estava encenando histórias alheias. O crítico Carlos Alberto Matos, na "faixa

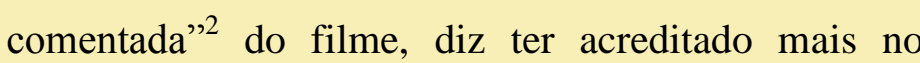
depoimento de uma determinada mulher que no de uma outra que contou a mesma história, mas, quando foi assistir aos extras, foi surpreendido pela descoberta de que aquela em quem ele havia depositado sua confiança, a qual julgou ter dado um depoimento “mais verdadeiro", era, na verdade, a atriz. 
Isso acontece porque o filme ora usa recursos de comparação de discursos, ora não usa recurso algum, deixando em pauta o indecifrado, o misterioso, o que permeia as estruturas mais profundas do psicológico e do social que nos engendram. A partir da montagem fílmica, as falas são fragmentadas, os assuntos repetidos, os discursos refeitos e colados uns aos outros, assumindo uma forma mosaica, a qual podemos relacionar com a maneira como atua a memória, descontínua e imprevisível, em meio a recortes e colagens de lembranças, esquecimentos e fabulações. O que interessa no documentário de Eduardo Coutinho, segundo Lins (2004), é a "memória do presente", a alteração que suas lembranças imprimem no presente, em seu corpo, gestos, voz e na sua vida. "Narrar, nesse sentido, já é uma prática, ativa, produtiva".

A mistura entre atrizes famosas e atrizes desconhecidas parece-nos uma tentativa não apenas de demonstrar a incapacidade de discernimento entre o discurso falso e o verdadeiro, mas de igualar o aspecto teatral entre eles. Sem diferenças de qualidade na atuação, o que está em jogo é revelar a representatividade atrelada à realidade de forma coletiva. Todas as mulheres são desta maneira, produtoras de discursos próprios e, ao mesmo tempo e necessariamente, usurpadoras de discursos alheios, evidenciando não mais o nível superficial de verdade e mentira na mensagem fílmica, mas o caráter social das memórias que passam a ser vistas como coletivas. Lins (2004, p.33), fundamentada em Ricouer (1979), diz que 
Dessa feita, percebemos que memória e discurso se retroalimentam, para a sustentação dos sentidos que regem a sociedade. $O$ acervo de memórias sociais representa a mola mestra que impulsiona a produção de novos discursos a partir dos outros que ainda vivem sustentados por ela.

Sendo assim, todo discurso está permeado por outros discursos, numa teia onde não se pode encontrar um início, tampouco é o que nos interessa. Nosso objetivo aqui é entender a interdependência entre eles e a memória presente em Jogo de Cena, o que nos leva a pensar numa outra interdependência, envolvendo realidade e ficção, pois, assim como os discursos se apóiam na memória e vice-versa, o mesmo ocorre entre a narrativa documental e a ficcional.

A personagem Sarita passa a maior parte de seu depoimento falando a respeito dos rancores que guarda do relacionamento com a filha. Quando conta a história de Procurando Nemo, um filme ficcional de desenho animado do qual ela diz gostar muito, vemos a personagem se emocionar de forma abrupta. Essa emoção pode soar estranha, até o momento em que Sarita revela achar o filme bonito porque "o filho temperamental se reconciliou com o pai”. A memória de Sarita, ao entrar em contato com o filme, que usa artifícios de produção de sentidos baseados no mundo real, o único mundo ao qual todos os seres humanos podem ter acesso e a partir do qual podem "criar" suas histórias ficcionais, fez ligações entre a ficção de Nemo e a realidade de seu passado. Relacionamos, pois, essa situação ao pensamento de Nichols (2005), quando afirma que, além de haver em todo documentário uma parcela de ficção, há também em toda ficção uma parcela do mundo real, este mundo constituído pelos discursos das memórias sociais.

\section{O fio da memória}

Diz-se que o cinema documental atua como arquivo de um tempo, como memória de um presente pretérito que se atualiza durante os vários presentes em que se perpetua. Pois se o tempo que o cinema 
registra é um tempo que passou, é o registro da morte, ele é também o que ainda vive, é como a memória que revive a cada nova atualização.

Dito de outro modo, o cinema tem como função o armazenamento da memória que está em constante transformação. Não somente no sentido das imagens, mas da própria memória que, com o tempo, vai modificando o seu olhar sobre o passado, não deixando, porém, de acreditar que pode, mesmo assim, manter uma essência imutável na coerência dos fatos. Tal coerência seria a base do mundo real, a qual só pode se efetivar a partir dessa continuidade, permeada pelos diversos devires, que se estabelece a partir da memória, afinal a lembrança, como explica Halbwachs (2004, p.76), "é uma imagem engajada em outras imagens".

O engajamento ao qual o autor se refere é o que faz da memória um dispositivo social, pois, através do processo de sua construção, incorpora discursos de diferentes indivíduos sociais. Para além da formação da memória, o autor aponta que as lembranças podem, a partir da vivência social, ser reconstruídas ou simuladas. Podemos criar representações do passado assentadas na percepção de outras pessoas, no que imaginamos ter acontecido ou pela internalização de representações de uma memória histórica. Ao entrar em contato com as lembranças de outros sobre pontos comuns em nossas vidas, acabamos por expandir nossa percepção do passado, contando com informações dadas por outros. Logo, quando, diante de uma câmera, um personagem lembra e conta sua vida, essa memória não pode ser classificada apenas como individual. Trata-se do que o filósofo Ricouer (2007) define como a constituição mútua, cruzada, de uma memória pessoal e de uma memória coletiva.

Em contrapartida, não há memória que seja somente "imaginação pura e simples" ou representação histórica que tenhamos construído que nos seja exterior, isto é, todo esse processo de construção da memória passa por um referencial que é o sujeito (HALBWACHS, 2004). Esses sujeitos, ao 
3 Coutinho caracteriza como pane o momento no qual a atriz Fernanda Torres não consegue continuar a representar a história da personagem Aleta. A atriz fica cerca de 20 minutos em "pane", mas logo depois 20 mine depois consegue retomar o texto e continuar a encenşa, inclusive adicionando uma experiência de sua vida pessoal no final de seu depoimento compartilharem suas memórias enquanto parte de um mundo comum, constroem o fio que os garante a verdade do passado e a realidade do presente. Em Jogo de Cena, as histórias sustentadas pelos depoimentos nada mais são que visões sobre o passado, no qual o testemunho revê o que passou, com os olhos do presente. Esta contaminação da memória do passado pelo presente funda um novo ângulo de vista sobre a história que é contada e, portanto, não salvo de fabulação, o que não podemos caracterizar como verdade, mas uma visão sobre ela.

Se questionamos até que ponto essas mulheres estão contando a verdade de suas vidas, foi porque quando vimos (e ouvimos) a repetição dessas histórias sendo encenadas por atrizes, passamos a refletir sobre a natureza do discurso testemunhal. Quando é inserido na narrativa um novo elemento, a "verdade" em meio à encenação, nos momentos em que as atrizes adicionam às histórias alheias fragmentos de suas vidas, podemos fazer um paralelo com o caráter social da memória, com o compartilhar e assimilar de histórias pessoais entre os indivíduos, com o construir um passado onde já não se pode separar o "meu" e o "seu", porque nossos discursos, circulando e flertandose pelo caminho, acabam por convergir na complexidade do "nós".

A memória, apesar de considerada como manifestação da vida que sustenta as certezas dos indivíduos e dos grupos, tem em sua força, ao mesmo tempo, sua fraqueza, porque, ainda que garanta uma coesão para transmissão dos discursos que ilustram o que entendemos por mundo real, assim como as certezas científicas que sustentam a vida e promovem o desenvolvimento humano, não há como fugir de sua inconfiabilidade. Afinal, nós acreditamos na memória porque é o único dispositivo que possuímos para nos mostrar o que passou e entender o que ficou. "Entendemos o mundo presente num contexto que se liga causalmente a acontecimentos e objectos do passado [...]" (CONNERTON, 1993, p.2). Mas nada nos garante que isso que imaginamos que passou, 
passou realmente, porque não temos a quem perguntar senão a nós mesmos.

\section{A verdade é uma mentira?}

O cenário fixo composto por cadeiras vazias de um teatro mostra-nos o nosso lugar de espectadores diante do espetáculo. Mas as personagens, não creditadas durante as entrevistas, mulheres "sem nome", estão de costas para o lugar destinado à plateia, reforçando a ideia de que não são elas, mas suas histórias, suas memórias, seus depoimentos, seu testemunho de vida, quem representa o papel principal. Se houvesse um público ali sentado, não poderia ver as diversas faces que marcam, de forma imponente, a identidade humana, a individualidade, mas poderia ouvir as vozes, as narrações, os depoimentos desencarnados, livres de autores específicos, depoimentos individuais e ao mesmo tempo coletivos, memórias compartilhadas socialmente.
Lembremos aqui de uma antológica cena do cinema europeu no filme Persona, do diretor Ingmar Bergman, em que a personagem de uma atriz suga o sangue do ferimento de sua enfermeira. $O$ filme mostra duas mulheres convivendo juntas, que passam a confundir-se ou, até mesmo, fundir-se uma a outra. Personalidades entrelaçadas, mundos opostos tornando-se um. O sugar o sangue representa ali uma apropriação da personalidade da outra, um interiorizar da essência alheia, da vida que não a pertence.

Podemos notar em Jogo de Cena duas passagens em que isso acontece. Marília Pêra, interpretando a história de Sarita, usa o termo "chiquerésimo" aplicando-o a um outro objeto diferente do que Sarita usou. Enquanto a personagem adjetiva sua filha como "chiquerésima", a atriz, lembrando do termo, mas esquecendo do objeto, acaba aplicando-o a uma outra frase, atribuindo o "chiquerésimo" a um apartamento. Coutinho diz, durante a faixa comentada, que não quis que nenhuma atriz decorasse as histórias; segundo ele, os vídeos 
com os depoimentos foram entregues com a seguinte recomendação: "Não imite e não critique". Assim, o que interessava para o diretor era exatamente a memória do presente, com todas as alterações que podem vir sobre ela.

Uma situação parecida com essa ocorre com a atriz Fernanda Torres, que interpreta o depoimento de Aleta. A expressão “Que loucura!” marca bastante a fala da personagem e, consequentemente, se fixa na memória de Fernanda. Quando passa por um questionamento do diretor acerca de saber se a atriz está se achando próxima a Aleta real, Fernanda passa por um momento de "pane"1, como considerou Coutinho. Ela responde que não sabe, porque não consegue separar a Aleta do que Aleta diz, parece que depoimento e personagem assumem um só corpo. Nesse momento, a atriz pára tudo o que está fazendo e,

${ }^{1}$ Coutinho caracteriza como pane o momento no qual a atriz Fernanda Torres não consegue continuar a representar a história da personagem Aleta. A atriz fica cerca de 20 minutos em "pane", mas logo depois consegue retomar o texto e continuar a encenação, inclusive adicionando uma experiência de sua vida Dossiê Cinema e Audiovisual: entre o sensível e o reflexivo pessoal no final de seu depoimento. depois, retoma e, aparentemente de maneira completamente involuntária e inconsciente, se apropria da expressão de Aleta, dizendo em referência à situação que está passando: “Que loucura... Que loucura!".

A partir da frase de Fernanda Torres, traça-se um paradoxo com a ideia do filme: a quem pertence os discursos? Parece-nos que a própria reação de Fernanda, incorporando expressões da personagem, já contradiz o que disse inicialmente. Aleta não é sua fala, e, se o é, então ela pode, enquanto memória, permear a individualidade de outras pessoas. Assim como nas personagens de Persona, Aleta dissolve-se em Fernanda. Como aconteceu com o "chiquerésimo" de Sarita (será mesmo “dela”?) em relação à Marília.

Assim, o filme leva-nos a um jogo em que o objetivo inicial parece ser descobrir onde está a verdade e a mentira nas falas das personagens, mas, paulatinamente, revela-nos que tal questionamento acerca da confiabilidade já não faz sentido quando o que importa efetivamente é a forma como se 
constroem os depoimentos, essas memórias atuadas e representadas com tudo o que têm de lembrança, esquecimento, fabulação, invenção e vontade de verdade. O que importa já não é julgar quem está mentindo; as mulheres tão expressivas perdem sua face frente ao poder de seus discursos que ganham autonomia e liberdade de circulação dentro da narrativa. As falas desencarnam, e o que permanece em jogo são seus poderes de mutação submetidos às artimanhas da memória.

No momento da "pane" de Fernanda Torres, ela diz para Coutinho: "Parece que eu estou mentindo pra você". E explica que o fato de saber que essa personagem existe e que seu discurso é a história de vida dela, a atriz se sente usurpadora da vida de alguém real, por isso diz parecer estar mentindo. A memória de Fernanda está, nessa situação, subordinada aos princípios de natureza da representação. Por não se tratar de uma personagem fictícia, a memória da atriz, comprometida com o sentido estabelecido para a "representação", acusa-a de estar sinalizando para o caminho errado e isso a impede de continuar. Segundo Fernanda, para interpretar, é preciso se convencer de sua própria mentira e quando você toma consciência dela, você cai.

\section{Considerações finais}

Ao analisarmos os temas centrais de Jogo de Cena, observamos que se resumem a assuntos que fazem parte do que entendemos por "universo feminino", pois, quando se anulam as faces, desencarnam-se os depoimentos, vemos que existem alguns elementos essenciais das falas pertencentes a ele. São assuntos como a maternidade, o relacionamento entre pais e filhos, a morte, a solidão e o abandono pelos homens. Nesse universo feminino, as verdades relativas ao masculino não fogem dos clichês do tipo homens são "autoritários", "infiéis", "mentirosos", “insensíveis", “egoístas”, isso, claro, excluindo os homens enquanto filhos, porque, nesse caso em especial, o discurso de que a maternidade é 
benevolente, a tudo perdoa e ama incondicionalmente, supera todas as maldades do caráter masculino. Vemos, assim, que os depoimentos que orbitam em torno de referenciais de verdade atribuídos pelas mulheres aos homens são discursos que, como disse Foucault (1995, p.22) “'se dizem', no correr dos dias e das trocas".

Isso não quer dizer que há, de um lado, a categoria dada uma vez por todas, dos discursos fundamentais ou criadores; e, de outro, a massa daqueles que repetem e comentam. Para Foucault (1995), esse desnivelamento nada mais é senão um jogo. Jogo de um comentário que se faz reaparição, palavra por palavra, daquilo que ele comenta. São discursos que reaparecem sem cessar, em todo frescor, a partir das coisas, dos sentimentos ou dos pensamentos, graças ao poder da memória. Em meio às repetições, o novo não está no que é dito, mas no acontecimento de sua volta, na máscara à qual lhe foi atribuída a sua reaparição.
É nesse sentido que devolvemos às personagens de Jogo de Cena a posse de suas falas. Seus depoimentos desencarnados podem voltar a seus corpos. As mulheres do filme passam, então, a ser autoras, mas não como indivíduos falantes que pronunciaram um texto, e sim atribuindo ao termo "autor" o conceito que Foucault (1995, p. 26-28) nos disponibiliza: como "princípio de agrupamento do discurso, como unidade e origem de suas significações, como foco de sua coerência”, o autor é "esse homem que irrompe em meio a todas as palavras usadas, trazendo nelas seu gênio ou sua desordem”, é aquele que "dá à inquietante linguagem da ficção suas unidades, seus nós de coerência, sua inserção no real".

\section{Referências}

BERNARDET, Jean Claude. Cineastas e Imagens do Povo. São Paulo: Companhia das Letras, 2003.

CONNERTON, P. Como as Sociedades Recordam. Oeiras: Celta Editora, 1993. 
DELEUZE, G. A Imagem-Tempo. São Paulo: Brasiliense, 2007.

FOUCAULT, M. A Ordem do Discurso. São Paulo: Loyola, 1995.

HALBWACHS, M. A Memória Coletiva. São Paulo: Centauro, 2006.

LINS, C. O Documentário de Eduardo Coutinho: televisão, cinema e vídeo. Rio de Janeiro: Jorge Zahar Ed., 2004.

NICHOLS, B. Introdução ao Documentário. São Paulo: Papirus, 2005.

NORA, P Entre a Memória e a História: a problemática dos lugares. Projeto História, n. 10, p. $7-$ 28, dez. 1993.

RAMOS, F. P. Mas Afinal... O que é Mesmo Documentário? São Paulo: Senac, 2008.

RICOUER, P. A Memória, a História, o Esquecimento. Campinas, SP: Editora da UNICAMP, 2007. 